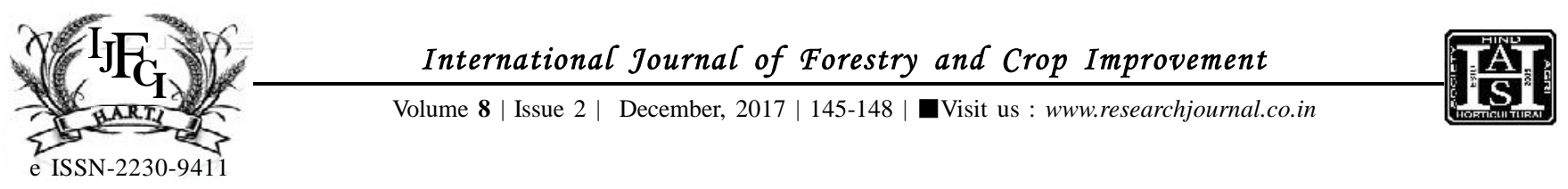

A REVIEW

DOI: $10.15740 / \mathrm{HAS} / \mathrm{IJFCI} / 8.2 / 145-148$

\title{
Metagenomics approach in forest ecosystem
}

\author{
SATYABRATANAYAK
}

\begin{abstract}
Forest ecosystems come under some of the most complex microbial community on Earth. Forest soil is an assemblage of archaea, bacteria, fungi, and protists, who play a crucial role in biogeochemical cycles. The soil ecology, biogeochemistry, microbial community structure serves as an indicator of forest ecosystem status, energy flow pattern and soil productivity. But it is difficult to determine the microbial composition, diversity and variability of forest soil as about $99.5 \%$ of micro-organisms cannot be cultured and grown in laboratory condition. Metagenomics is a culture-independent genomic analysis of microorganisms, directly obtained from the environment and can be used to tackle such problems which are assisted by rRNA universal markers, next-generation sequencing techniques, and bioinformatics tools. Attempts have been made by scientists to explore the forest microbiomes through metagenomics approach have been reviewed in this article. Metagenomics analysis has been carried out in various type of forest soils to access the microbial genetic resources and to know the phylogenetic diversity and abundance of a particular forest type, which helps in understanding their role in the forest ecosystem. As per the future line of work, it is needed to apply metagenomics in accumulating information across diverse forest habitat types which will help in better understanding the role of micro-organisms in the forest ecosystem, how they are helpful against different abiotic stresses, diseases, and other ecosystem functions.
\end{abstract}

KEY WORDS : Metagenomics, Next-generation sequencing, Bioinformatics tools, Forest ecosystem

How TO CITE THIS ARTICLE : Nayak, Satyabrata (2017). Metagenomics approach in forest ecosystem. Internat. J. Forestry \& Crop Improv., 8 (2) : 145-148, DOI: 10.15740/HAS/IJFCI/8.2/145-148.

ARTICle ChroniCAL : Received : 17.06.2017; Accepted : 29.11.2017

\section{AUTHOR FOR CORRESPONDENCE}

SATYABRATA NAYAK, Department of Tree Physiology and Breeding, College of Forestry, Kerala Agricultural University, Vellanikkara, THRISSUR (KERALA) INDIA Email: satya3bapuni@gmail.com 